\title{
Prostate Gland
}

National Cancer Institute

\section{Source}

National Cancer Institute. Prostate Gland. NCI Thesaurus. Code C12410.

The walnut shaped accessory sex gland of the male reproductive system. It is located in the pelvis just below the bladder, surrounding the prostatic part of the urethra. The prostate gland secretes a fluid which is part of the semen. 